\title{
Comparison of Effectiveness in National Olympic Sporting Organizations of Iran and Iraq
}

\author{
Hossein Eydi ${ }^{1, *}$, Homayon Abbasi ${ }^{1}$, Ako Ibrahim $^{2}$ \\ ${ }^{1}$ Department of Physical Education and Sport Science, University of Razi, Kermanshah, Iran \\ ${ }^{2}$ Sport Science institute of Iraq, University of Holler \\ *Corresponding Author: eydihossein@gmail.com
}

Copyright (C) 2013 Horizon Research Publishing All rights reserved.

\begin{abstract}
Measurement of organizational performance and effectiveness are very important in their strategic decision making and evaluate of sporting organization's successes. This study used the Competing Values Approach (CVA) for comparison of the organizational effectiveness model of sporting federations in Iran and Iraq. Population of study consists of all sporting federations in Iran and Iraq, and the sample was stakeholders (board of directors, professional employees, national referees, athletes and coaches) of 6 selected federations of Iran (basketball, volleyball, handball, wrestling, weightlifting and Taekwondo) and 4 selected federations of Iraq (basketball, Football, weightlifting and track and field) that selected according to a goal oriented method. Finally, three hundred sixty tow constituents from 6 NOSO of Iran and one hundred eighty four constituents from 4 NOSOs of Iraq participated in this study. Self-management OE questionnaire of Eydi and et al (2012) according to Shilbury \& Moore (2006) scale, applied for research. Result of confirmatory factor analysis showed that productivity, stability and resource in NOSOs of Iran and productivity, interaction and work force expert in NOSO of Iraq was the critical determinant of organizational effectiveness in NOSOs.
\end{abstract}

Keywords Organizational Effectiveness, Competing Framework, Iran, Iraq Value

\section{Introduction}

Organizational effectiveness is a theoretical core of all organizational models and it is final dependant variable in most organizational studies [14]. The multiple approaches Model is also useful when there are different sets of stakeholders with varying goals [16]. Typically these approaches only focus on a specific aspect or dimension of effectiveness. Widely acknowledged models are the goal attainment approach, the system resource approach, the internal process approach, the social function model, the multiple constituency model and competing values approach $[2,5]$.

The goal attainment approach, the system resource approach and the internal process approach if the theoretical model to apply cannot be considered reliable and adequate criteria in measuring organizational effectiveness. Because their orientation is one-dimensional (For example, the emphasis goal attainment approach on output) and focus on only a dimension. This issue is a very sensitive in nonprofit organizations, because Nonprofit organizations such as sports federations develop their activities in various fields, Pursue multiple goals and are active with the attitude Multiple stakeholders satisfaction and regard to changes and growing demands against the external environment [4].

Thus, due to difficulties in obtaining a reliable model for measuring organizational effectiveness, Some researchers of Sports Management such as Chelladurai (1987) [11] Frisby (1986) [22] and Koksi (1995) [12] suggest organizations need to be evaluated with different parameters Simultaneously and so the use of a multi-dimensional approach.

Review the history of sports organizations effectiveness showed that study the of these variable peaked during 1980 and early 1990 and researchers such as Chelladurai and Danylchuk (1984) [13] Chelladurai, Haggerty, Campbell \& Wall (1981) [15] Chelladurai, Szyszlo \& Haggerty (1987) [14] and Frisby (1986) [22] used these variable studied in sports organizations, but the process trend was downward after a period. Recently, interest to effectiveness studies has been strong in sports organizations and researchers such as Bayle \& Madella (2002) [6] Papadimitriou \& Taylor (2000) [4] Wolfe \& Putler (2002) [19] Shilbury \& Moore (2006) [5] Papadimitriou (2007) [3] and Balduck (2009) [2] eydi et al (2012) [7] and Ibrahim (2013) [1] studied Effectiveness in sport organizations.

There are several studies that have been studied organizational effectiveness in sports organizations and federations. For example, Quinn and Spreitzer's (1991) [17] competing value framework was used extensively for measurement organizational culture and concluded that this 
measurement had better reliability and validity. Also, Kalliath, Bluedorn \& Gillespie (1999) [9] extend the competing values framework of Quinn and his colleagues by using structural equation modeling (LISREL) to test the CVF and refine a scale that identifies the extent to which managers and other organizational constituencies use the framework's criteria to evaluate organizational effectiveness. Based on a sample of 300 hospital managers and supervisors, with one exception, their results support the CVF.

Papadimitriou \& Taylor (2000) [4] use the multiple constituency model of organizational effectiveness to a sample of Hellenic national sports organizations (NSOs). Factor analysis resulted in the extraction of five composite effectiveness variables including calibre of the board and external liaisons, interest in athletes, internal procedures, long-term planning and sport science support that formed multi-dimensional nature of the effectiveness measurement.

Shilbury \& Moore (2006) [5] use the competing values approach (CVA) of organizational effectiveness to a sample of nonprofit Australian national Olympic sporting organizations (NOSOs). The purpose of the study was to determine the psychometric properties of the subscales developed within the four quadrants the CVA. By using structural equation modeling (LISREL) showed that the rational-goal model is highlight part and determinants of organizational effectiveness in the competitive value approach.

Balduck (2009) [2] investigated management and program effectiveness using the competing values approach as a theoretical framework at Belgian sport clubs and showed the dimension satisfaction, competition goal, acquiring sports members, and information and communication were significant predictors of the program effectiveness level.

Rojas (2000) [19] study literature review of nonprofit organizational effectiveness from which four models of organizational effectiveness was selected. Results showed that the competing values approach is the most proper approach to evaluating organizational effectiveness in nonprofit organizations. On the other hand, Shilbury \& Moore (2006) stated that multiple constituency Model is as requirements and it is components of the competing values approach. Thus, the most effective of multi-dimensional approach is competing values approach of Quinn \& Rohrbaugh (1981) [18].

Competing values approach to the multi-dimensional nature and cover other approaches was selected as theoretical framework for this study. This approach is composed four quadrant including the open systems model, the rational-goal model, the internal process model and the human relations model and eight sub factors including flexibility, organizational resource, planning, productivity, organizational interaction, stability, work force cohesion and work force expert [8, 19, 21].

The literature review of organizational effectiveness in sport showed that there are different approaches to measuring organizational effectiveness. However, an approach is useful for organizations that have a particular combination of environmental and organizational attitudes. On the other hand, organizations can be effective and achieve their goals, if evaluates their internal and external environment; because organizations are to face with different environments, Produce different products and are in different stages of development and their stakeholders are people with different views. Thus, a comprehensive model does evaluate organizational effectiveness of all organizations. On the other hand, all organizations have Own unique goals and they try to achieve these goals. Thus, using a theoretical approach and similar definition of organizational effectiveness for measuring effectiveness of these different organizations may have different results. Therefore, it is essential that researchers to find local models and choose the most appropriate criteria for measuring organizational effectiveness $[2,20]$.

Regard to the role and importance of sporting federations in Iran and Iraq, their very important functions and their dependence on governmental funding for providing their services and programs should be accountable for their performance. The strategic constituencies approach has been the precursor to the CVA and it is therefore logical to extend the measurement of effectiveness incorporating constituent groups within the three dimensions composing the CVA. On one hand, increased government funding was demanding more accountability and professionalization in terms of management practice, and on the other hand, many national sporting organizations remained grounded in the traditional amateur values that had underpinned Iran and Iraq sport for most of its history. With paradox and contradiction in NOSOs evident, together with the conceptual and measurement ambiguity associated with nonprofits, using the CVA to measure organizational effectiveness is further reinforced.

However, comparison of organizational effectiveness in tow neighbor country, gives important information about situation of effectiveness in tow country with cultural and structural difference.

\section{Methodology}

The population for this study consisted constituencies (board of directors, professional employees, national referees, athletes and coaches) of six NOSOs (summer sports mean basketball, volleyball, handball, wrestling, weightlifting and taekwondo) of Iran and four selected federations of Iraq (basketball, Football, weightlifting and track and field) that selected according to a goal oriented method. Finally, 362 constituents from six NOSO of Iran and 184 constituents from four NOSOs of Iraq participated in this study

Eydi and et al (2012) [7] questionnaire based on Shilbury and Moore (2006) [5] Organizational effectiveness questionnaire on a four quadrant of human relations model, Internal process, rational-goal model, open systems model and eight sub factors of flexibility, resources, planning, productivity, organizational interaction, Stability, worked 
force cohesion and worked force expert used for study. Also, validity of questionnaire with use of Cronbach alpha was $84 \%$. The LISREL software used to path analyzes and designing model and the confirmatory factor analysis (CFA) applied to design model of effectiveness in NOSOs.

\section{Results}

Structural equation modeling was used to load each summated factor onto its respective latent factor, and the intercorrelations among these latent factors were examined.

Result Figure1, showed the intercoreletion among factors in Iran NOSOs that were positive correlation among all factors. Also, rational-goal model (productivity and planning) and open system model (flexibility, organizational recourse) showed the most of relations with each sub factors. Finally, all models has relations with each other that among them, relationship between rational-goal model and open system model $(r=630 / 0)$ was most.

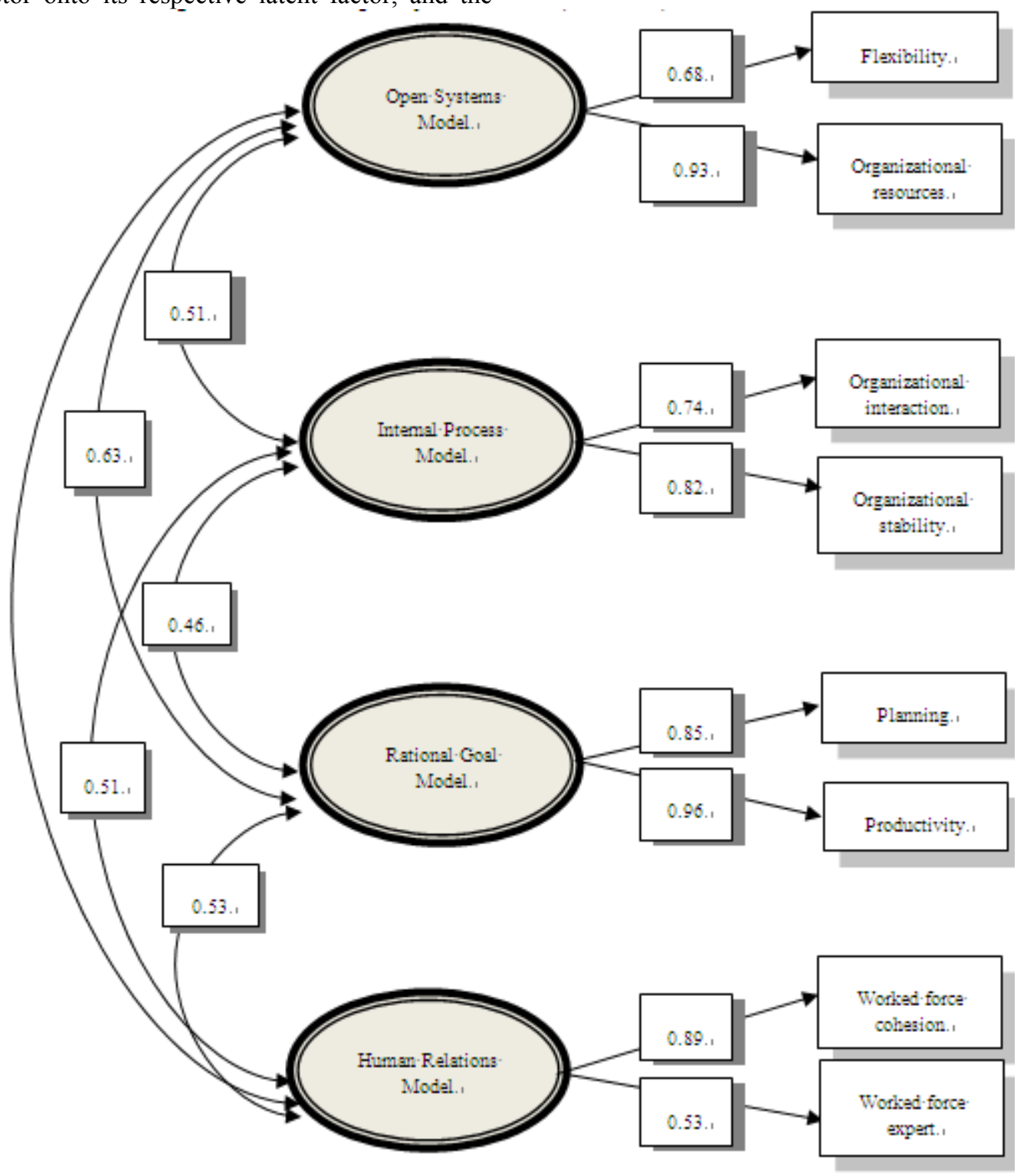

Figure 1. Intercoreletion Among Factors in Iran NOSOs

According to figure 2, confirmatory factor analysis of organizational effectiveness in Iran NOSOs, showed that eight factor has a direct correlation to organizational effectiveness. Productivity, recourse and stability had high correlation to organization effectiveness and this

Factors are main determinants of organizational effectiveness in Iran sporting federations. 


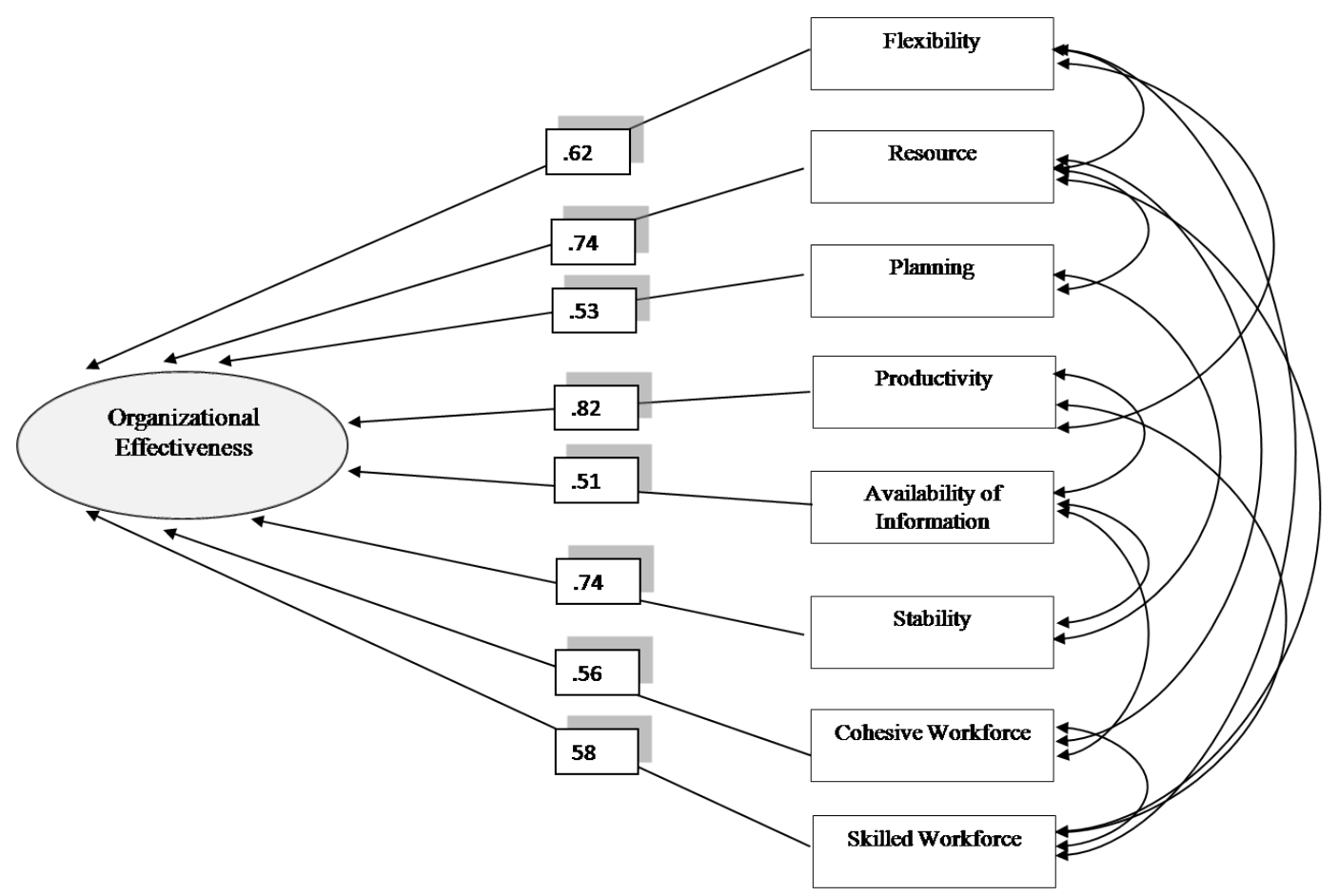

Chi- Square $=26.50, \quad \mathrm{df}=9, \quad \mathrm{RMSEA}=.039$

Figure 2. Confirmatory Factor Analysis of Organizational Effectiveness in Iran NOSOs

Figure 3, showed the intercoreletion among factors in Iraq NOSOs that were positive correlation among all factors. Also, rational-goal model (productivity and planning) and human resource model (cohesive work force, expert work force) showed the most of relations with each sub factors. Finally, all models has relationship with each other that among them, relationship between rational-goal model and human resource model $(r=97$ 0/0) was most.

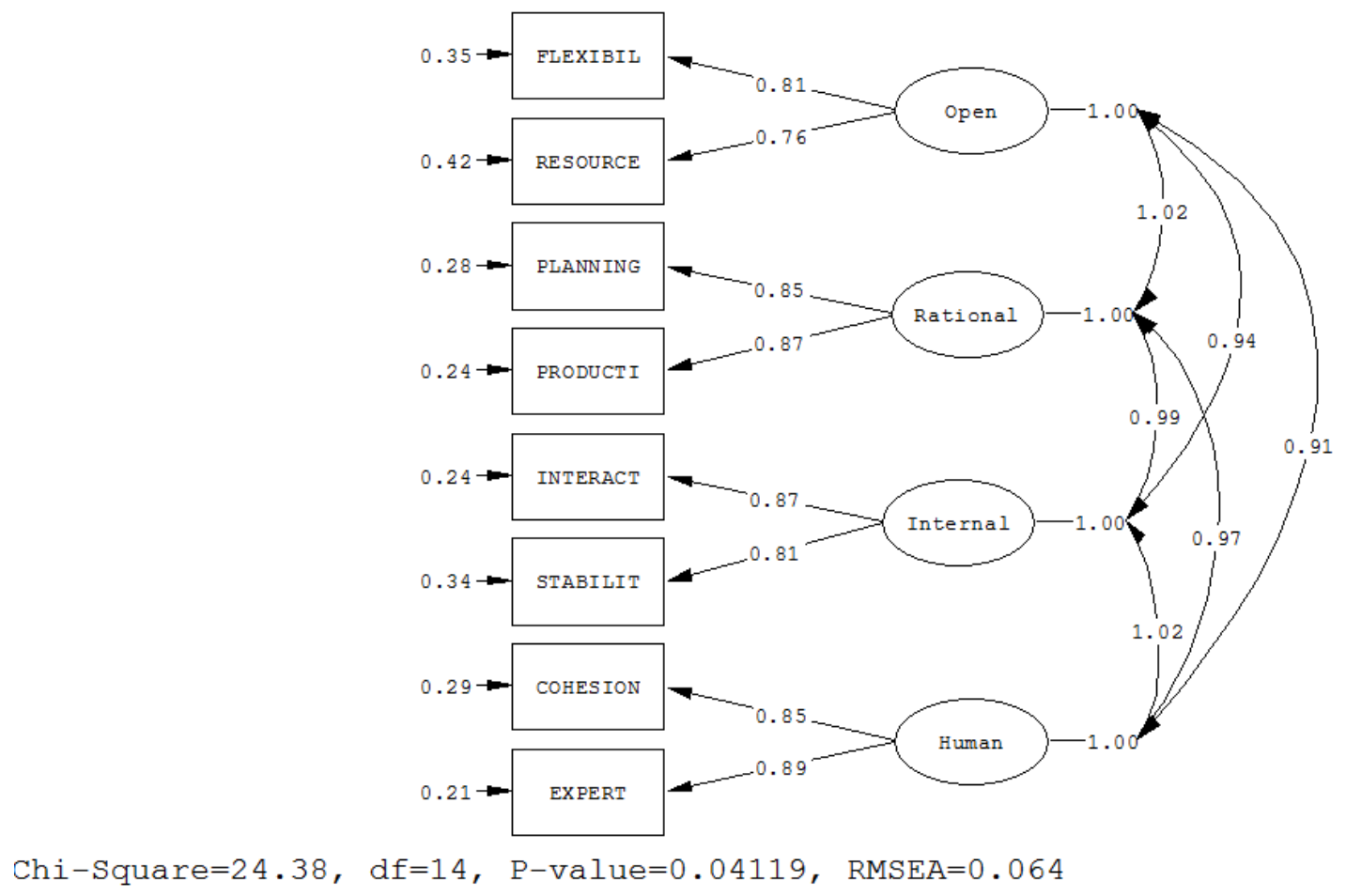

Figure 3. Intercoreletion Among Factors in Iraq NOSOs 
According to figure 4, confirmatory factor analysis of organizational effectiveness in Iraq NOSOs, showed that eight factor has a direct correlation to organizational effectiveness. Productivity, interaction and expert work force had high correlation to organization effectiveness and these factors are main determinants of organizational effectiveness in Iraq sporting federations.

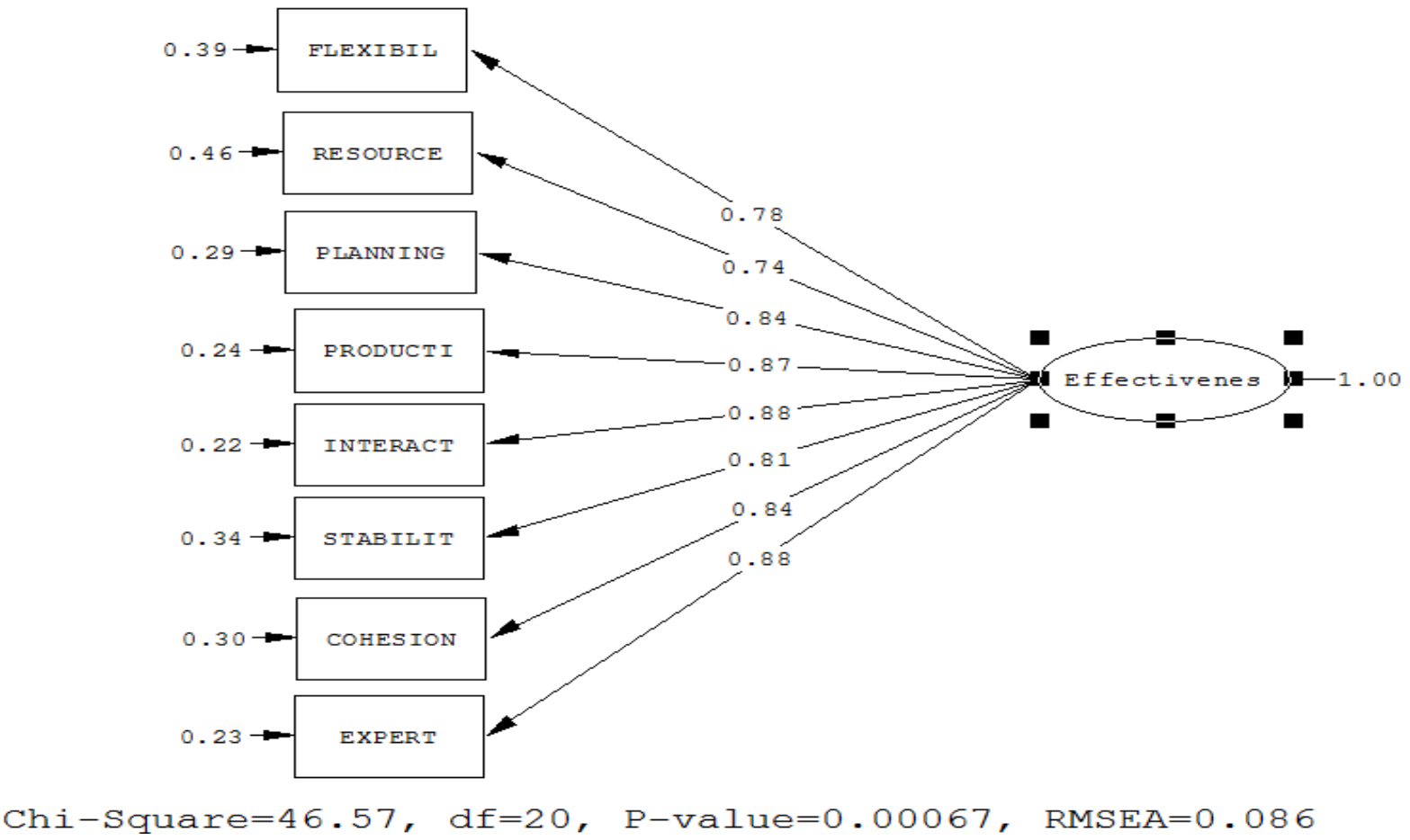

Figure 4. Confirmatory Factor Analysis of Organizational Effectiveness in Iraq NOSOs

\section{Conclusion}

The aim of this study was to comparison organizational effectiveness in national sporting organizations of Iran and Iraq based upon the dimensions of Quinn and Rohrbaugh's (1983, 1983) [18] competing values theory.

Construct validity of organizational effectiveness in sporting federations, results showed that eight sub factors of productivity and planning (rational-goal model), flexibility and resources (open system model), organizational interaction and Stability (internal process model) and worked force cohesion and worked force expert (human relations model) formed research model infrastructures based on competing values approach. Also, the similar patterns and sub factors applied in research of Shilbury \& Moore (2006) [5], Balduck (2009) [2], Eydi et al (2012) [7] and Kalliath, Bluedorn \& Gillespie (1999) [9].

According to the results of figure 1and 2, the rational-goal model and open systems model was key models of organizational effectiveness in the Iran sporting federations. Also, results of figure 2 showed that productivity, stability and resource was key factors of organizational effectiveness in Iran NOSOs. This result was congruent to Shilbury \& Moore (2006) [5] that reported in terms of the four quadrants composing the CVA, it is interesting to observe that aspects of three of these quadrants, Productivity (rational-goal quadrant), Flexibility (open systems quadrant), and Stability (internal process quadrant), were the three major contributors and markers in their respective quadrants.

In other side, results of figure 3 and 4 showed that, the rational-goal model, internal process model and human resource model, were key models of organizational effectiveness in the Iraq sporting federations. Also, results of figure 2 showed that productivity, interaction and work force expert was key factors of organizational effectiveness in NOSOs of Iraq. This result was congruent some to extent with Shilbury \& Moore (2006) [5], Balduck (2009) [2], Eydi et al (2012) [7] and Ibrahim (2013) [2] that they reported productivity as a key factor.

It is interesting those organizational resources (e.g., players, coaches, officials, funding, sponsorship) demonstrated the lowest correlation with organizational effectiveness in Iraq NOSOs. This result congruent to Shilbury \& Moore (2006) [5] who reported that resource acquisition, is an ongoing challenge. In other words, a sport will continue to attract players, coaches, and officials despite the state of its internal operations.

According to results of path analysis, productivity (based on satisfaction of sporting federations such as athletes, coaches, referees and staff) as valuable indicator of competing values approach in Iran and Iraq NOSOs, support to meet the expectations and needs of highlighted stakeholders of sporting Federations to achieve organizational effectiveness [19]. On the other hand, elite 
athletes are most prominent stakeholder of sporting federations and had most impact on organizational outcomes in sporting federations. Thus, with keeping the satisfaction of highlight stakeholder, sporting federations can be successful in achieving to their final goals [3]. Also, important of other stakeholder's satisfaction in sporting federations (staff, sponsors and etc) that emphasized on customer orientation to achieving and measuring organizational effectiveness is consistent with background of organizational effectiveness $[4,10,19]$. Attention to Stakeholders satisfaction criteria indicate that most of the sporting federations focus on the goals of championship and professional level than public aspects and sport development. This is especially true in connection with the Iran sport that more budgets was applied on elite sport than sports development. However, in the sports federations there are rarely necessary coordination between the needs and expectations of elite athletes for preparation and participation in international sporting events and also provide programs and services for athletes. Thus, special considerations must be made about the needs and expectations of the athletes and coach as a second key stakeholder of sporting federation. Because, success of elite sport in international stage bring national pride to society and message of success for organizational success.

The other results support the claim that the resource (based on financial, human, hardware and software resources) is the foundation of organizational effectiveness and one of most important determinants of organizational effectiveness in sporting federations of Iran, though, were lowest important in Iraq.

In elite sport system of Iran and Iraq, most of the sporting federations tend that greater financial resources attract from the Ministry of Youth and Sports to invest in wide range of sport plan. Based on organizational effectiveness systems theory, organizational effectiveness focuses on the organization's ability to attract resources from the environment to ensure the preservation of his life [24] were analyzed of 149 scholarly publications published in field of organizational effectiveness and job performance and concluded that profit organizations mainly are focus on economic and financial criteria, while nonprofit organizations such as the sporting federations have priority over humanitarian and social consequences and community issues within the organization.

An examination of the intercorrelations among the variables revealed that all four models were highly correlated in Iraq in comparison to Iran; this interdependence was interpreted to suggest that these 8 separate factors may be better represented as contributing to one latent variable, that is, organizational effectiveness.

Comparison between organizational effectiveness of tow neighbor country showed similar and different attitude related to organizational effectiveness. For example, The productivity (based on satisfaction of sporting federations such as athletes, coaches, referees and staff), which was best seen through early efforts to examine effectiveness [the goal approach, Price, 1968]), as the sole measure of effectiveness is counterintuitive to the multidimensional nature of the CVA in Iran and Iraq NOSOs, which in essence recognizes and reinforces the view that no one model of effectiveness is capable of defining and measuring effectiveness. In other side, we saw resource as a key factor of effectiveness in Iran NOSOs, whereas in Iraq NOSOs, this factor was lowest important. One of justification for this result may be attention of Iranian NOSOs to external environment (flexibility and resource) and attention of Iraqis NOSOs to internal environment (interaction and stability).

Finally remark, we express that the suggested eight factor model provides a conceptual framework to operationalize the effectiveness construct in sporting organizations. Furthermore, the adopted CVA ensures much more convincing evidence of the acceptability of the proposed model by different interest groups. One of the advantages of the CVA is its capacity to visually articulate effectiveness results on each of the four models and eight cells. Visualization in this form, referred to as an amoebagram, allows managers to quickly ascertain strengths and weaknesses of an organization in terms of effectiveness. Overall levels of effectiveness are shown, but more important, the perceptions of effectiveness of each of the major constituent groups can also be plotted onto the CVA [1, $2,5,7]$.

\section{REFERENCES}

[1] A. Ibrahim, M. Hamatineghad, R. Ramezanineghad, H. Eydi, Organizational Effectiveness of Iraq Sport Federations, Sport management international journal, Choregia, 9 (1) 70-85, 2013.

[2] A., L. Balduck, Management and Program Effectiveness in Belgian Sports Clubs Working paper series, Faculty of Economics and Business Administration, Ghent University, pp. 1-26, 2009.

[3] D., Papadimitriou, Conceptualizing effectiveness in a non-profit organizational environment, International Journal of Public Sector Management, Vol. 20 No. 7, 2007.

[4] D., Papadimitriou, R. Taylor, Organizational effectiveness of Hellenic national sports organizations: A multiple constituency approach. Sport Management Review, 3, 23-46, 2000 .

[5] D., Shilbury, K. A. Moore, A study of organizational effectiveness for National Olympic Sporting Organizations. Nonprofit and Voluntary Sector Quarterly, 35(1), 5-38, 2006.

[6] E., Bayle, A. Madella, Development of taxonomy of performance for national sport organizations. European Journal of Sport Science, 2(2), 1-21, 2002.

[7] H., Eydi, R, Ramezanineghad, B, yousefi, S.N Sajjadi, Designing Model of organizational effectiveness in sporting Federations of Iran. Sport management journal of Mazandaran, 14, 6-21, 2012.

[8] H., Eydi, R, Ramezanineghad, B. yousefi, S.N. Sajjadi, 
Malekakhlagh, E Compressive review of organizational effectiveness in sport. Sport management international journal, Choregia, 7 (1) 6-21, 2011.

[9] J., Kalliath, A. C., Bluedorn, D. F. Gillespie, A confirmatory factor analysis of the competing values instrument. Educational and Psychological Measurement, 59(1), 143-158, 1999.

[10] K., Cameron, Effectiveness as paradox: Consensus and conflict in conceptions of organizational effectiveness. Management Science, 32, 539-553, 1986.

[11] P., Chelladurai, Multidimensionality and multiple perspectives of organizational effectiveness. Journal of Sport Management, 1, 37-47, 1987.

[12] P., Koski, Organizational effectiveness of Finnish sporting clubs. Journal of Sport Management, 9, 85-95, 1995.

[13] P., Chelladurai, K. E. Danylchuk, Operative goals of intercollegiate athletics: Perceptions of athletic administrators. Canadian Journal of Applied Sport Sciences, 9, 33-41, 1984.

[14] P., Chelladurai, M., Szyszlo, T. R. Haggerty, Systems-based dimensions of effectiveness: The case of national sport organizations. Canadian Journal of Sport Science, 12, 111-119, 1987.

[15] P., Chelladurai, T. R., Haggerty, L., Campbell, S. A, Wall factor analytic study of effectiveness criteria in intercollegiate athletics. Canadian Journal of Applied Sport Science, 6, 81-86, 1981.

[16] R. D., Herman, D. O. Renz, Multiple Constituencies and the Social Construction of Nonprofit Organization Effectiveness. Nonprofit and Voluntary Sector Quarterly, 26, 185-206,
1997.

[17] R. E., Quinn, G. M. Spreitzer, The psychometrics of the competing values culture instrument and an analysis of the impact of organizational culture on quality of life. Research in Organizational Change and Development, 5, 115-142, 1991.

[18] R. E., Quinn, J. Rohrbaugh, A spatial model of effectiveness criteria: Towards a competing values approach to organizational analysis. Management Science, 29, 363-377, 1983.

[19] R. R. Rojas, A review of models for measuring organizational effectiveness among for-profit and nonprofit organizations. Nonprofit Management \& Leadership, 11(1), 97-104, 2000.

[20] R. Wolfe, D. Putler, How tight is the ties that bind stakeholder groups? Multiple constituency approach. Academy of Management Review, 5, 211 -217. Organization Science, 13, 64-80, 2002.

[21] T., Slack, B. Parent, Understanding sport organizations: The application of organization theory. Champaign,IL: Human Kinetics, 2006.

[22] W. Frisby, Measuring the organizational effectiveness of national sport Governing bodies. Canadian Journal of Applied Sport Science, 11, 94-99, 1986.

[23] W., Morrow, P. Chelladurai. The structure and processes of Synchro Canada. Journal of Sport Management, 6, 133-152, 1992.

[24] Y., Baruh, \& N. Ramalho, Communalities and Distinctions in the Measurement of Organizational Performance and Effectiveness across For-Profit and Nonprofit Sectors. Nonprofit and Voluntary Sector Quarterly, 35(1), 39-65, 2006. 